\title{
Los mandatos de los Organismos Reguladores ¿son actos administrativos o son reglamentos?
}

\author{
"Ustedes hagan la Ley, que yo haré el Reglamento" \\ ÁLVARO DE FIGUEROA Y TORRES \\ I CONDE DE ROMANONES
}

\section{Giancarlo Vignolo Cueva*}

Resumen. - En el presente artículo, el autor establece a qué figura jurídica pertenecen los Mandatos de los Organismos Reguladores. Es así que se desarrolla una comparaciòn entre la figura de los actos administrativos y los reglamentos. Finalmente, se demuestra que los Mandatos son actos administrativos no normativos, y que estos se tramitan a través de procedimientos trilaterales especiales.

\begin{abstract}
In this article, the author establishes to which legal figure the Mandates of the Regulators belong. A comparison is thus developed between administrative acts and regulations. Finally, it is demonstrated that Mandates are non-standard administrative acts, and that these are handled through special trilateral procedures.

Palabras claves. - Derecho Público - Organismos Reguladores - Actos administrativos - Procedimiento administrativo - Reglamentos.
\end{abstract}

Keywords. - Public Law - Regulators - Acts of Administration- Administrative Procedure - Regulation.

* Asociado Senior del Departamento de Derecho Público (Administrativo y Regulatorio) del Estudio Garrigues (Oficina Lima). Ex consultor de la Dirección de Licenciamiento de la Superintendencia nacional de Educación Superior Universitaria (SUNEDU). Ex abogado del Departamento Legal de la empresa Duke Energy Egenor S. en C. por A (hoy Orazul Energy Perù S.A. - empresa perteneciente al fondo I Square Capital). Magíster en Finanzas \& Derecho Corporativo - con especializaciones en Regulaciòn de Servicios Públicos y Gestión de Asociaciones Público-Privadas - por la Universidad ESAN. Especialista en Derecho de la Energía y Derecho Administrativo Sancionador. Abogado por la Facultad de Derecho de la Universidad de Piura (UDEP), adscrito al Ilustre Colegio de Abogados de Lima (CAL). Profesor universitario, árbitro e investigador jurídico. 


\section{Naturaleza jurídica de los Organismos Reguladores}

De conformidad con lo establecido en la Ley Orgánica del Poder Ejecutivo, Ley N 29158 (en adelante, la "LOPE") y la Ley Marco de Organismos Reguladores de la Inversión Privada en los Servicios Públicos, Ley No 27332 (en adelante, la "LMOR"), los Organismos Reguladores (que a la fecha1 son OSIPTEL, OSINERGMIN, OSITRAN y SUNASS 2 ) son entidades desconcentradas del Poder Ejecutivo, con personería jurídica de Derecho Público, con competencia a nivel nacional y se encuentran adscritos a la Presidencia del Consejo de Ministros (PCM).

Se encuadran dentro de la categoría de "Organismos Públicos Especializados" y se crean o nacen para actuar en ámbitos especializados de regulación de mercados o para garantizar el adecuado funcionamiento de mercados no regulados, asegurando cobertura de atención en todo el territorio nacional, permitiendo "un marco institucional de seguridad y estabilidad en las reglas de juego y la inversión, aislados de los vaivenes políticos, (...)"3.

Estos organismos tuvieron sus orígenes en Inglaterra. Al respecto, Richard Martin Tirado precisa que "uno de los principios aplicables al régimen jurídico de la concesión administrativa, fue el conocido como "quien concede no debe controlar". Este concepto, aplicado a la experiencia inglesa, y luego llevado a la práctica de algunos países latinoamericanos, implica que el Estado (concedente en los contratos de concesión) en su condición de parte contractual, no podría someter a su libre arbitrio el control sobre las actividades que desarrolla su contraparte (el concesionario). En función a ello, se hacía necesario a la luz de las experiencias internacionales existentes sobre el tema, fijar un marco legal a través de los mecanismos de la denominada "regulación económica", y dentro de ellos, fomentar el diseño y puesta en funcionamiento de las "agencias de regulación", las mismas que en nuestro país son conocidas como "Organismos Reguladores de Inversión Privada en Servicios Públicos" 4.

1 Resaltamos la frase "a la fecha", pues el Tribunal Constitucional - mediante la Sentencia de fecha 15 de agosto de 2019, recaída en el Expediente No 05410-2015-PA/TC (Sociedad Minera Cerro Verde vs. OEFA - Aportes por Regulación) -, al parecer habría otorgado la naturaleza de Organismo Regulador al Organismo de Evaluación y Fiscalización Ambiental (OEFA), aunque aún es una materia no pacífica.

2 Son el Organismo Supervisor de la Inversión Privada en Telecomunicaciones, el Organismo Supervisor de la Inversión en Energía y Minería, el Organismo Supervisor de la Inversión en Infraestructura de Transportes de Uso Público y la Superintendencia Nacional de Servicios de Saneamiento, respectivamente.

3 TASSANO VELAOCHAGA, Hebert, "Los Organismos Reguladores de Servicios Públicos", Revista de Derecho Administrativo (CDA) No 4, Círculo de Derecho Administrativo de la Pontificia Universidad Católica del Perú, Lima, 2008, p. 90.

4 MARTIN TIRADO, Richard, "Análisis de la "función normativa" de los Organismos Reguladores de Inversión Privada en los Servicios Públicos. La dicotomía del rol del Estado en la actividad económica: subsidiariedad y solidaridad", en Revista Ius Et Veritas No 24, Pontifica Universidad Católica del Perú, Lima, 2002, p. 94. 
En este contexto, podemos señalar que los Organismos Reguladores son verdaderas Administraciones Públicas de carácter especial5, institucional6 e instrumental7. Es decir, se configuran como una "organización del Poder Público que actúa con potestad administrativa, en función del interés general " 8 , que realiza actuaciones heterogéneas para cumplir sus finalidades públicas, pudiendo emitir actos administrativos que finalmente crean, modifican y/o extinguen derechos $\mathrm{u}$ obligaciones de los administrados bajo su competencia.

Cabe mencionar que, los Organismos Reguladores tienen asignadas una serie de facultades o potestades, tales como (i) la función supervisora; (ii) la función reguladora; (iii) la función normativa; (iv) la función fiscalizadora y sancionadora; (v) la función de solución de controversias; y, (vi) la función de solución de reclamos de usuarios.

\section{Los mandatos de los Organismos Reguladores}

La emisión de mandatos por parte de los Organismos Reguladores (en adelante, los "Mandato(s)") ha sido incluida por el legislador, para bien o para mal, dentro de la función normativa de dichas Administraciones Públicas.

La referida potestad normativa comprende la facultad de estas entidades para dictar reglamentos, normas que regulen procedimientos administrativos y otras de carácter general además de emitir Mandatos u otras normas de carácter particular referidas a intereses, obligaciones o derechos de las entidades o administrados supervisados, incluyendo también la facultad de tipificar infracciones y establecer la escala de multas y sanciones.

La normatividad específica ha establecido que los Mandatos son emitidos y expedidos mediante resoluciones de los órganos máximos de estas Administraciones; vale decir, por el Consejo Directivo de los Organismos Reguladores.

Además estos Mandatos contienen obligaciones de hacer, no hacer y/ o cargas para determinados administrados bajo su competencia, a efectos de permitir o hacer posible el acceso y uso, por parte de determinados concesionarios u operadores, de cierta infraestructura asociada a la prestación de servicios públicos de energía eléctrica, hidrocarburos, telecomunicaciones, redes viales, entre otras, de titularidad de otros concesionarios u operadores, facilitando así el despliegue y la interconexión de redes necesarias para la prestación o provisión de determinados

5 Es de carácter "especial" pues sólo tiene atribuidas funciones específicas sobre un determinado sector de actuación (energía, telecomunicaciones, hidrocarburos, saneamiento, entre otros).

6 Es de carácter "institucional" pues han sido creadas con la finalidad de gestionar un determinado interés o conjunto de intereses públicos, dotándolas de un determinado grado de autonomía.

7 Son "instrumentales" toda vez que, según el profesor MARTíNEZ LÓPEZ-MUÑIZ son "organizaciones dotadas de cierta autonomía relativa con respecto a una organización pública superior, corporativa o estrictamente institucional, de la que dependen y a la que sirven".

8 ABRUÑA PUYOL, Antonio, “Delimitación jurídica de la Administración Pública en el ordenamiento peruano", Palestra Editores, Lima, 2010, p. 67. 
servicios a la sociedad.

Cabe mencionar que los Mandatos son emitidos por los Organismos Reguladores normalmente, (i) por solicitud de uno de los concesionarios $\mathrm{u}$ operadores involucrados y (ii) luego que ambos concesionarios u operadores no llegan a un acuerdo voluntario de interconexión o compartición de infraestructura o, habiendo llegado a un acuerdo, las actividades de operación y mantenimiento de la infraestructura interconectada o compartida se ve impedida o entorpecida de realizar por acciones del otro concesionario u operador.

\section{Actos administrativos y los reglamentos: diferencias y similitudes}

Ahora bien, a efectos de determinar si un Mandato emitido por un Organismo Regulador califica como un acto administrativo normativo (es decir, como una norma reglamentaria o reglamento) o como un acto administrativo no normativo, primero procederemos a definir las características de cada uno, así como establecer los mecanismos legales para su cuestionamiento por parte de los administrados.

\section{i. Los actos administrativos}

La Administración Pública realiza actuaciones heterogéneas, siendo la gran mayoría, "actos administrativos" que ostentan elementos comunes que los hacen identificables.

Los "actos administrativos" se definen como "toda declaración de la Administración Pública que trae como consecuencia la producción de efectos jurídicos en ejercicio de una potestad administrativa" 9 , cuyos elementos comunes son:

(i) su procedencia subjetiva, pues siempre son emitidos por una Administración Pública;

(ii) producen efectos jurídicos que afecten, de alguna manera, la realidad o la situación jurídica de uno o varios administrados, creando, modificando o extinguiendo sus deberes, derechos, cargas, entre otros; $y$,

(iii) reflejan el modo de actuar propio de la Administración Pública pues, en el ejercicio de una potestad administrativa atribuida por el legislador, expedirá el acto administrativo con un contenido declarativo.

9 ABRUÑA PUYOL, Antonio, "Sobre el así denominado concepto estricto de acto administrativo", en Revista Foro Académico No 15, 2016, pág. 252. Al respecto, existe una controversia respecto de la noción de acto administrativo, entre quienes defienden un concepto más amplio de acto administrativo, que incluye las declaraciones de voluntad, juicio, conocimiento y deseo (como el propio DR. ABRUÑA), y quienes defienden una noción más estricta (como lo hace, en el Perú, HUAPAYA TAPIA, Ramón, "Propuesta de una nueva interpretación del concepto de acto administrativo contenido en la LPAG", en Administración Pública, Derecho administrativo y regulación. Estudios y Cuestiones. Ara Editores, Lima, 2011, pp. 149 y ss.). Esta discusión alcanza a la inclusión de los reglamentos dentro de la noción de acto administrativo. 
Para poder emitir un acto administrativo, la Administración Pública deberá seguir un previo procedimiento administrativo, que es el cauce formal de la serie de actos en que se concreta la actuación administrativa para la realización de un fin. El procedimiento administrativo es un camino obligatorio de la Administración Pública para poder expedir un acto administrativo, siendo a su vez una garantía de los derechos de los administrados.

Sobre el particular, el artículo $1^{\circ}$ del Texto Único Ordenado (TUO) de la LPAG, aprobado mediante Decreto Supremo N 004-2019-JUS (en adelante, el “TUO de la LPAG" $^{\prime \prime}$, precisa que son actos administrativos las declaraciones de las entidades que, en el marco de normas de derecho público, están destinadas a producir efectos jurídicos sobre los intereses, obligaciones o derechos de los administrados dentro de una situación concreta, no siendo actos administrativos los actos de administración interna y las actividades materiales de la Administración.

\section{ii. Los Reglamentos}

Por "reglamento" se entiende a aquella norma escrita, secundaria, infra legal y complementaria a una Ley, que es emitida por una Administración Pública, en ejercicio de una potestad normativa o reglamentaria asignada expresamente por una norma con rango de Ley. El reglamento sólo opera en los ámbitos en que la Ley los habilite, siendo su sumisión total a la norma legal. Cabe mencionar que la potestad reglamentaria es el poder en virtud del cual la Administración Pública dicta reglamentos, siendo hoy en día su uso de tal magnitud, que el número de reglamentos emitidos por la Administración es superior al número de leyes vigentes emitidas por el Parlamento.

Al respecto, el numeral 118.8 del artículo $118^{\circ}$ de la Constitución Política del Perú (en adelante, la “ $\mathrm{CP}^{\prime}$ ) y los artículos $6^{\circ}$ y $8^{\circ}$ de la LOPE señalan que corresponde al Presidente de la República ejercer la potestad de reglamentar las leyes sin transgredirlas ni desnaturalizarlas, pudiendo las demás entidades emitir estos reglamentos, en caso exista una norma legal habilitante.

Entre los requisitos de validez de un reglamento o norma reglamentaria, tenemos (i) que debe provenir de un órgano de la Administración Pública investida con potestad reglamentaria (a través de una norma legal); (ii) que el reglamento emitido aborde materias que no han sido reservadas a la Ley, por mandato constitucional (como por ejemplo, impuestos); (iii) que respete el Principio de Primacía de la Ley; (iv) que sea emitido por una Administración que tiene competencia sobre la materia; y (v) que haya seguido un procedimiento para su emisión, establecido por la "Guía para la elaboración de proyectos de normas reglamentarias" del Ministerio de Justicia y Derechos Humanos - MINJUS (no emitida hasta la fecha, hasta donde conocemos) además de cumplir con su publicación en el Diario Oficial "El Peruano".

Cabe precisar que, de conformidad con el numeral 3 del Artículo II del Título 
Preliminar del TUO de la LPAG, las autoridades administrativas, al reglamentar los procedimientos especiales, deben observar y cumplir con los principios administrativos, así como con los derechos y deberes de los sujetos del procedimiento, establecidos en la referida ley (Principio de Legalidad, Simplicidad, Debido Procedimiento, entre otros).

En este contexto, nos planteamos la pregunta si los reglamentos son actos administrativos o son una cuestión distinta.

Por un lado, algunos autores consideran que los reglamentos son un tipo especial de acto administrativo (los actos administrativos normativos, frente a los actos administrativos no normativos), en tanto ponen el énfasis en que se trata de declaraciones productoras de efectos jurídicos, dictadas por una Administración Pública, en ejercicio de una potestad administrativa.

Por su parte, otros autores ponen en el énfasis en lo que distingue ambas figuras (el carácter normativo o no del acto), de modo que reservan la categoría acto administrativo para aquellos que no son normasio.

Al respecto, más allá de la discusión conceptual, el TUO de la LPAG define al acto administrativo como aquella declaración destinada a producir efectos jurídicos "dentro de una situación concreta". Por tanto, dicha norma únicamente admite su aplicación al procedimiento para dictar actos administrativos no normativos (y no reglamentos), por lo que en nuestro país adquiere especial relevancia la distinción entre acto y norma.

\section{iii. Criterios diferenciadores de ambas categorías}

Un primer criterio de diferenciación lo podemos ubicar en la "generalidad", que sería propia de los actos administrativos normativos (reglamentos) y no lo sería respecto de los actos no normativos (a los cuales se les aplicaría el criterio de "singularidad"). Sin embargo, es una noción de difícil aprehensión y aplicación pues, en la práctica, existen actos administrativos no normativos que están dirigidos a una pluralidad indeterminada de administrados11 (generales) y actos administrativos normativos (reglamentos) dirigidos a un solo administrado12

10 Sobre esta discusión, puede verse ABRUÑA PUYOL, Antonio y BACA ONETO, Víctor, “El Reglamento, ¿acto administrativo en el Derecho Peruano?, En Revista de Derecho de la Universidad de Piura, 11, 2010, pp. 71 y ss. No obstante, incluso quienes sostienen esta última posición no pueden dejar de reconocer que "la circunstancia de que el reglamento siga un régimen distinto al del acto administrativo singular sólo quiere decir que el reglamento no puede ser considerado como un acto administrativo singular, pero ello no quita que sea posible formular un concepto que los englobe a los dos". DANÓs ORDOÑEZ, Jorge, "¿Constituye el acto administrativo fuente del Derecho en el ordenamiento jurídico peruano?", en RODRÍGUEZ ARANA, Jaime, BENAVIDES PINILLA, Víctor, SCHEFFER TUÑÓN, Javier y SENDÍN GARCÍA, Miguel Ánguel (EDS.), 2009, p. 613.

11 Por ejemplo, podemos mencionar que un acto administrativo no normativo que está dirigido a una cantidad indeterminada de administrados, sería una "convocatoria pública".

12 Sobre el particular, podemos mencionar, como ejemplo, a la "Directiva sobre el Procedimiento Aplicable para el Reconocimiento de las Inversiones y las Labores de Mantenimiento Correctivo en el Segundo Grupo de Aeropuertos de Provincia de la República del Perú", aprobada mediante Resolución de Consejo Directivo $N^{\circ}$ 022-2018-CD/OSITRAN, que se configura como un reglamento 
(singulares). En ese sentido, el criterio de la generalidad se ha dejado de lado.

$\mathrm{Al}$ respecto De Otto13 menciona que:

"uno de los criterios utilizados para distinguir los reglamentos de los actos administrativos - el otro contenido posible de las mismas formas que los reglamentos revisten - es el de la generalidad. (...) Los reglamentos, por tanto, serían normas generales, que afectan a una pluralidad indeterminada de ciudadanos, mientras que los actos administrativos serían singulares. Aunque este criterio es válido, en la mayor parte de los casos no es, sin embargo, enteramente correcto y la doctrina no lo considera suficiente. La razón [no] está, como en el caso de la ley, en que haya reglamentos individuales, posibilidad remota, sino en que actos administrativos cuya naturaleza de tales no se discute, tienen, sin embargo, un carácter general. Así ocurre con unas oposiciones o con ciertas órdenes de policía, por ejemplo, la prohibición de transitar por un determinado lugar".

Otro criterio es el denominado "criterio ordinamental", el cual plantea la diferencia a partir de la fuerza innovadora del ordenamiento jurídico que tiene la norma reglamentaria (acto ordinamental) - la cual se integra al ordenamiento y se convierte en fuente de derecho - y de la que carecen los actos no normativos (actos ordenados). La fuerza innovadora del ordenamiento es el "criterio mínimo y esencial, que no puede fallar" 14 . Sin embargo, este criterio es insuficiente pues decir que una norma es el acto que altera el conjunto de normas es indubitablemente cierto, pero en realidad no precisa mucho.

Por lo tanto, el criterio anterior debe completarse con otro criterio como es el de la "no consunción", el cual resulta aplicable a los actos administrativos normativos o reglamentos. Sobre el particular, los profesores Eduardo García de Enterría y Tomás-Ramón Fernández señalan que el acto administrativo no normativo "sea singular o general su círculo de destinatarios, se agota en su simple cumplimiento, se consume en éste; para un nuevo cumplimiento, habrá que dictar eventualmente un nuevo acto (...) En cambio, la norma ordinamental no se consume con su cumplimiento singular, antes bien se afirma, se consolida, se mantiene y es susceptible de una pluralidad indefinida de cumplimiento; sigue "ordenando" la vida social desde su superioridad" 15 . Cabe mencionar que este criterio está ligado a la "abstracción", que suele predicarse de las normas y no de los actos no normativos.

En virtud a lo señalado anteriormente, estaremos ante la presencia de un acto

autónomo que regula la situación jurídica de un solo administrado, la Sociedad Concesionaria Aeropuertos Andinos del Perú S.A.

13 DE OTTO, Ignacio, "Derecho Constitucional. Sistema de fuentes", Quinta reimpresión de la Segunda Edición, Ariel Derecho, Barcelona, 1997, pp. 215 - 216.

14 MEILÁN GIL, José Luis, La distinción entre norma y acto administrativo, ENAP, Madrid, 1967, pp. 36 y ss. Más recientemente, puede verse la posición del mismo autor en: “El acto administrativo como categoría jurídica", en El acto administrativo como fuente del Derecho administrativo en Iberoamérica, Congrex, Panamá, 2009, pp. 392 y ss.

15 GARCÍA DE ENTERRÍA, Eduardo y FERNÁNDEZ RODRÍGUEZ, Tomás Ramón, Curso de Derecho Administrativo Volumen I, 13ª Edición, Civitas, Madrid, 2006, pp. 189 - 190. 
administrativo normativo o reglamento cuando el mismo innove el ordenamiento (criterio ordinamental - norma jurídica) además de no agotarse o consumirse con su aplicación singular (criterio de no consunción), surtiendo efectos hasta que sea derogado o expulsado del ordenamiento jurídico (similar a lo que ocurre con una norma legal). Por el contrario, el acto administrativo no normativo no tendrá naturaleza innovadora del ordenamiento, sino que será la materialización de la aplicación de una norma legal y/o reglamentaria, agotándose o consumiéndose con su sola aplicación particular, ya sea que el destinatario del acto sea un solo administrado o sean varios de estos (plural).

Podemos mencionar que a partir de un juego de los conceptos abstracción/concreción (en función a que el supuesto de hecho sea determinado o indeterminado) y generalidad/singularidad (en función a que el destinatario sea determinado o indeterminado), es posible distinguir hasta cuatro (4) tipos de regulaciones16: (i) abstractas-generales, (ii) concretas-singulares, (iii) abstractassingulares y (iv) concretas-generales.

Si un supuesto de hecho es abstracto y los destinarios son generales (abstractasgenerales), claramente estaremos frente a una norma reglamentaria. Por el contrario, si el supuesto de hecho es concreto y el destinario es singular, estaremos ante un acto administrativo no normativo (concretas-singulares). Las dos regulaciones intermedias (abstractas-singulares y concretas-generales) no son claras de ubicar a priori en una $u$ otra clasificación, siendo que, salvo que exista una norma expresa que determine su naturaleza, deberán aplicarse los criterios ordinamental y de no consunción, a efectos de determinar su naturaleza jurídica en cada caso concreto; es decir, si estamos frente a un acto administrativo no normativo o frente a un reglamento.

\section{iv. Diferencias adicionales: Revocabilidad y notificación}

Una diferencia adicional entre reglamentos y actos administrativos no normativos se encuentra en que los reglamentos son siempre revocables, incluso por motivos de oportunidad (a través de su derogación mediante otra norma de similar rango, otro reglamento), mientras que los actos administrativos no normativos no pueden serlo, por prohibición legal17.

Asimismo, para los actos normativos rige el "Principio de Inderogabilidad Singular de los Reglamentos", que limita o impide que la Administración se aparte en un caso concreto de lo dispuesto por un reglamento, lo que no ocurre con un

16 Para mayor profundidad sobre esta materia ver SANTAMARÍA PASTOR, Juan Alfonso, "Fundamentos de Derecho Administrativo", Volumen I, Centro de Estudios Ramón Areces, Madrid, 1988, pp. $723-725$.

17 TUO de la LPAG

Artículo 214.- Revocación

(...)

214.2 Los actos administrativos declarativos o constitutivos de derechos o intereses legítimos no pueden ser revocados, modificados o sustituidos de oficio por razones de oportunidad, mérito o conveniencia. 
acto administrativo no normativo. Finalmente, el procedimiento de elaboración y emisión de unos es distinto al de los otros, siendo que el procedimiento administrativo de los actos administrativos no normativos se encuentra regulado por el TUO de la LPAG, y el de los actos administrativos no normativos, como ya hemos mencionado, aún se encuentra en elaboración por el MINJUS (ver la Séptima Disposición Complementaria Final del TUO de la LPAG), aplicándose a la fecha normas especiales.

Con relación a la entrada vigencia de un acto administrativo de carácter no normativo y uno normativo, tenemos que los artículos $16^{\circ}, 17^{\circ}$ y $20^{\circ}$ del TUO de la LPAG establecen que al acto administrativo no normativo es eficaz a partir de su notificación legalmente realizada, salvo que el acto no normativo otorgue beneficios al administrado, pues en esta situación se entiende eficaz desde la fecha de su emisión.

La notificación del acto no normativo es practicada de oficio, debiendo realizarse en día y hora hábil, siguiendo el orden de prelación del tipo de notificación predeterminado por el TUO de la LPAG; es decir, como regla general, la notificación personal y, en su defecto, mediante publicación en el Diario Oficial " $E l$ Peruano" y en uno de los diarios de mayor circulación en el territorio nacional, bajo apercibimiento de nulidad de la notificación, en caso de no seguir dicha prelación. El artículo $23^{\circ}$ del TUO de la LPAG también señala que los actos administrativos no normativos de alcance general o que interesan a un número indeterminado de administrados no apersonados y con domicilio desconocido, deberá ser notificado mediante la publicación antes precisada.

Con relación a los reglamentos, el artículo $109^{\circ}$ de la CP y el numeral 7 del artículo $4^{\circ}$ y el artículo $7^{\circ}$ del Decreto Supremo $N^{\circ}$ 001-2009-JUS, que aprueba el Reglamento que establece disposiciones relativas a la publicidad, publicación de Proyectos Normativos y difusión de Normas Legales de Alcance General, han establecido como regla general para su entrada vigencia, la publicación en el Diario Oficial "El Peruano", siendo obligatorio a partir del día siguiente de publicado.

\section{v. Mecanismos de impugnación de los actos administrativos y los reglamentos}

La diferencia entre acto no normativo y reglamento es de gran importancia, porque ambas categorías se remiten a regímenes jurídicos diferentes. Entre estas diferencias, tienen especial importancia los mecanismos mediante los cuales se cuestiona la validez de cada uno de estos actos. Así, en caso nos encontremos frente a actos administrativos no normativos, el administrado podrá impugnarlos primero, en vía administrativa (en el plazo de 15 días hábiles, como regla general), a través de los recursos de reconsideración y/o apelación, contemplados en los artículos $218^{\circ}$ y siguientes del TUO de la LPAG. Una vez agotada la vía administrativa, el administrado podrá plantear su correspondiente demanda contenciosa-administrativa en la vía judicial (en el plazo de 3 meses, como regla 
general), ello según lo dispone el artículo $148^{\circ}$ de la CP y el Texto Único Ordenado (TUO) de la Ley que regula el Proceso Contencioso Administrativo, aprobado mediante Decreto Supremo N 011-2019-JUS (en adelante, el “TUO de la LPCA”).

Por el contrario, si nos encontramos ante la presencia de un Reglamento, la ilegalidad o invalidez del mismo, en tanto se hubieran inobservado sus límites subjetivos, materiales y/o formales, se planteará a través de una acción constitucional denominada "Acción Popular". Al respecto, el numeral 200.5 del artículo $200^{\circ}$ de la CP y el Código Procesal Constitucional, aprobado mediante la Ley $\mathrm{N}^{\circ} 28237$, precisan que la presente garantía constitucional procede contra los reglamentos, normas administrativas y resoluciones y decretos de carácter general, cualquiera sea la autoridad de la que emanen, por infracción de la Constitución y de la Ley, o cuando estas normas no hayan sido expedidas o publicadas en la forma prescrita por la Constitución o la ley, según sea el caso. La demanda de Acción Popular puede ser interpuesta por cualquier persona, dentro del plazo de cinco (5) años contados desde el día siguiente de la publicación de la norma reglamentaria, siendo que las sentencias fundadas recaídas en el proceso de Acción Popular podrán determinar la nulidad, con efecto retroactivo, de las normas impugnadas. En tal supuesto, la sentencia determinará sus alcances en el tiempo. Dichas sentencias tienen efectos generales y se publican en el Diario Oficial "El Peruano".

Cabe precisar que, los argumentos antes detallados han sido reconocidos por el Poder Judicial, toda vez que, mediante la Resolución Nº 6 del Expediente Nº 89672015, la Primera Sala Contencioso Administrativo de la Corte Superior de Justicia de Lima (en adelante, la "Sala Contenciosa"), en el marco una apelación planteada por el demandante (América Móvil Perú S.A.C.) contra la Resolución N 4 del Noveno Juzgado Especializado en lo Contencioso Administrativo de Lima (en adelante, el "Juzgado"), que declaró fundada una Excepción de Incompetencia planteada por OSIPTEL, al considerar el Juzgado que una Resolución del Consejo Directivo de OSIPTEL tenía la naturaleza de reglamento y no de un acto administrativo no normativo. Sobre el particular, la Sala Contenciosa señaló lo siguiente:

\section{“SÉPTIMO: (...)}

De lo expuesto, se puede colegir que los elementos del acto administrativo son: a) Una declaración de cualquiera de las entidades - el acto es el resultado jurídico de un proceso de exteriorización intelectual, emanado de cualquiera de los órganos de las entidades, para concretar en un supuesto específico la potestad conferida por ley, por tanto conlleva fuerza vinculante por imperio del derecho-, b) Destinada a producir efectos jurídicos externos -la naturaleza de decisión ejecutoria es sustancial para la configuración del acto administrativo, pues solo mediante este acto, la autoridad puede crear, reconocer, modificar, transformas o cancelar intereses, obligaciones o derechos de los administrados, a partir del contenido del acto que aprueba-, c) Recae en derechos, intereses y obligaciones de los administrados -la calidad del acto administrativo queda reservada para aquellas decisiones que por sí mismas generar efectos jurídicos para los terceros, en sus 
derechos, intereses u obligaciones-, d) En una situación concreta característica del acto administrativo, es que los efectos subjetivos que producen son concretos, de materia y situación jurídico administrativa específica, lo que los diferencia de los reglamentos que son abstractos, generales e impersonales-; y, e) Puede tener efectos individualizados o individualizables -esto es, al momento de su dación, pues lo importante es que al momento de su ejecución, ya esté individualizado perfectamente.

\section{(...)}

OCTAVO: Respecto a las normas reglamentarias, debemos indicar que son definidas como instrumento jurídico de alcance general; en consecuencia, los reglamentos son una expresión de la potestad normativa mediante los cuales se crea Derecho y por ende se incorpora al ordenamiento jurídico con vocación de permanencia y no se consume con su cumplimiento, sino por el contrario, mientras esté en vigor, es susceptible de una pluralidad de aplicaciones; diferenciándose del acto administrativo, por cuanto este último se agota en su aplicación. Entre otras diferencias, tenemos que la potestad reglamentaria se encuentra atribuida exclusivamente a ciertos órganos; el procedimiento de elaboración de reglamentos y actos administrativos es diverso; la adquisición de eficacia se produce, en la mayor parte de las ocasiones, mediante instrumentos distintos (la publicación en todo caso para los reglamentos y la notificación, como regla general, para los actos administrativos que, en determinados supuestos, sin embargo, habrán de ser también publicados); existen mecanismos diversos para la retirada de la vida jurídica de una $\mathrm{u}$ otra figura (derogación, en el caso del reglamento y revocación en el caso del acto administrativo); el Reglamento inválido es nulo de pleno derecho, mientras que los actos administrativos pueden ser nulos o anulables; finalmente, son también distintos los sistemas de impugnación de una y otra figura".

\section{Ahora bien, ¿en qué categoría encajarían los mandatos de los Organismos Reguladores?}

A partir de las ideas antes esbozadas, corresponde ahora determinar si los Mandatos se configuran como actos administrativos no normativos o como verdaderos actos normativos o reglamentos La respuesta a la que arribemos, permitirá aplicarle consecuencias jurídicas distintas a una u otra categoría de acto.

\section{i. Los mandatos son actos administrativos no normativos}

Sobre el particular, si bien de una lectura literal de la LOPE, la LMOR, las leyes de creación de los Organismos Reguladores además de los reglamentos generales de los mismos, se desprende que la emisión de los Mandatos se encuadra dentro de su "función normativa", esto no puede llevarnos a concluir que dicho acto tiene la condición de acto administrativo normativo o, lo que es lo mismo, una norma reglamentaria. Nos explicamos.

El Mandato se configura, en primer término, en un acto administrativo. Es decir, es una declaración de voluntad de la Administración Pública (el Organismos 
Regulador competente), dictado en el ejercicio de una potestad administrativa atribuida por las distintas normas de rango legal (LOPE, LMOR y leyes de creación de cada Organismos Regulador), que produce efectos jurídicos individualizados en los derechos, intereses y obligaciones de un administrado singular (el concesionario u operador supervisado, bajo el ámbito de su competencia), imponiéndole una obligación de hacer, en la mayoría de casos (compartir su Infraestructura bajo determinadas condiciones) y que tiene una finalidad pública específica, consistente en permitir y facilitar el despliegue de redes de necesarias para la provisión de un determinado servicio público.

Aplicando los criterios diferenciadores, tenemos que lo siguiente:

a) Por el "criterio ordinamental", el Mandato no innova el ordenamiento jurídico peruano; es decir, en su contenido no se encuentra una norma jurídica con vocación de permanencia, sino por el contrario, se trataría de un acto administrativo no normativo, que se obtiene luego de aplicar otras normas legales y reglamentarias para su tramitación y correspondiente emisión;

b) Que el Mandato sea emitido por el órgano máximo del Organismo Regulador; es decir, por su Consejo Directivo, es simplemente una muestra del reparto de funciones ad intra de dicha Administración Pública, más no vuelve al referido Mandato en una norma reglamentaria, pues dicho órgano colegiado emite tanto actos administrativos normativos como no normativos. Como ejemplo podemos mencionar el "Procedimiento aplicable para la emisión de Mandatos de Compartición solicitados en el marco de la Ley $\mathrm{N}^{\circ}$ 29904", el cual fue aprobado mediante Resolución de Consejo Directivo $\mathrm{N}^{\circ}$ 026-2015-CD/OSIPTEL (en adelante, el "Procedimiento"), procedimiento que sirve de cauce para expedir los Mandatos de Compartición de Infraestructura, los cuales también son aprobados mediante el mismo ropaje externo; es decir, mediante Resoluciones de Consejo Directivo del OSIPTEL. A diferencia del Mandato en sí, el Procedimiento sí se configura como una verdadera norma reglamentaria, pues contiene en sí una norma jurídica con vocación de permanencia.

c) Aplicando el "criterio de no consunción", tenemos que el Mandato se agota o consume con su aplicación singular a un caso concreto, la orden de compartición o interconexión de dos (2) operadores en una situación específica, a diferencia - nuevamente - del Procedimiento que no se agota o consume con la aplicación a un caso concreto, sino que seguirá surtiendo efectos (para otros casos) hasta que sea derogado o expulsado del ordenamiento jurídico.

d) A partir de un juego de los conceptos abstracción/concreción y generalidad/singularidad, es posible distinguir que el Mandato, generalmente, se encuadra en un supuesto de hecho concreto y en un 
destinario singular o particular, por lo que válidamente podemos afirmar que estaríamos ante la presencia de un acto administrativo no normativo (situación concreta-singular), no pudiendo el Organismo Regulador revocar este acto no normativo por razones de oportunidad, como si podría hacerlo, por ejemplo, con el Procedimiento, a través de una norma derogatoria de similar rango.

e) Entendemos que generalmente los Mandatos, además de notificarse de manera personal en los domicilios de los administrados destinatarios, son publicados en el Diario Oficial "El Peruano", por parte del Organismo Regulador, con la única finalidad de no afectar los derechos y/o intereses de terceros administrados, además de permitirles poder defenderse, de ser el caso18, no pudiendo concluir que, por el solo hecho de que los Mandatos son publicados, adquieren la categoría de reglamento. Como bien ha señalado la Sala Contenciosa en el precedente que hemos citado previamente, la notificación como una condición de eficacia es característica de los actos no normativos, carácter que inequívocamente cabría atribuirle a los Mandatos emitidos por los Organismos Reguladores.

En este orden de ideas, tomando en consideración todo lo anteriormente afirmado, es posible concluir que los Mandatos de los Organismos Reguladores tienen la naturaleza jurídica de ser "actos administrativos no normativos, normalmente de carácter singular".

Es preciso hacer notar un error asumido por algunos autores, derivado de la inclusión de los Mandatos dentro de la llamada "función normativa" de los Organismos Reguladores. Así, dicha norma se refiere a los "mandatos u otras normas de carácter particular". Es decir, al parecer se incluye a los Mandatos dentro de la categoría de "normas de carácter particular", definidas como aquellas que son aplicables únicamente a una situación o persona, como las resoluciones que autorizan el viaje de funcionarios o las autorizaciones de funcionamiento de entidades bancarias.

Al respecto, de acuerdo al Sistema Peruano de Información Jurídica (SPIJ), de donde hemos extraído la referencia previa19, éstas "normas de carácter particular" se publican en la base de datos de actos administrativos, con los cuales en realidad comparten su naturaleza y régimen jurídico. Por ejemplo, podríamos recordar que de acuerdo a la LOPE, las "Resoluciones Supremas" son expresión de la función

18 TUO de la LPAG

Artículo 71.- Terceros administrados

(...)

71.3 Los terceros pueden apersonarse en cualquier estado del procedimiento, teniendo los mismos derechos y obligaciones de los participantes en él.

$19 \begin{array}{ll}\text { Sistema Peruano } & \text { de } \\ \text { http://spij.minjus.gob.pe/manuales/ManualUsuario.pdf }\end{array}$

Información

Jurídica: 
normativa del Presidente de la República, aun cuando no siempre sean verdaderas normas20.

Por tanto, las llamadas "normas de carácter particular" no son verdaderas normas, en tanto no son reglamentos. Es decir, de acuerdo a los criterios del TUO de la LPAG, no son "Fuente del Derecho Administrativo", sino actos administrativos no normativos, que tienen efectos en una situación concreta, conforme lo establece el artículo $1^{\circ}$ del TUO de la LPAG. En consecuencia, no corresponde impugnarlas mediante la Acción Popular21, la cual está reservada para cuestionar los reglamentos, normas administrativas, resoluciones y decretos de carácter general22.

\section{ii. Los mandatos se tramitan, generalmente, a través de procedimiento trilaterales especiales}

Con relación al procedimiento administrativo que sirve de cauce para la emisión de los Mandatos, tenemos que, como regla general, se trata de procedimientos administrativos trilaterales especiales, los cuales permiten dar trámite a las solicitudes de emisión de Mandatos de los administrados, contando con etapas definidas en las cuales las partes o administrados con posiciones disímiles pueden exponer sus argumentos y contradecir los de la otra parte, contando para ello con plazos adecuados. Asimismo, dichos procedimientos determinan normalmente los plazos en los cuales los Organismos Reguladores y los administrados deberán llevar a cabo sus respectivas actividades.

Al respecto, los artículos $229^{\circ}$ y siguientes del TUO de la LPAG, aplicables de manera supletoria a las reglas especiales contenidas en los reglamentos específicos de cada Organismos Regulador, determinan que el procedimiento trilateral es un procedimiento administrativo contencioso seguido entre dos (2) o más administrados ante las entidades de la Administración (los Organismos Reguladores). La parte que inicia el procedimiento con la presentación de una reclamación será designada como "reclamante" (el operador o concesionario afectado por la no interconexión o no compartición de infraestructura) y cualquiera de los emplazados será designado como "reclamado" (el operador o concesionario titular de la infraestructura que requiere ser compartida o a la cual se tiene la intención de interconectar el otro concesionario).

20 El texto del Decreto Legislativo $\mathrm{N}^{\circ} 560$ definía a las Resoluciones Supremas como "normas de carácter específico", pese a que no siempre tenían dicho carácter normativo.

21 Sobre el objeto de la Acción Popular, véase MORÓN URBINA, Juan Carlos, Análisis jurisprudencial del Proceso de Acción Popular en el Perú: Propuestas para mejorar el control jurisdiccional sobre las normas reglamentarias, pp. 70 y ss., Tesis para optar para el Grado de Magister con Mención en Derecho Constitucional en la PUCP, disponible en http://tesis.pucp.edu.pe/repositorio/handle/123456789/4504.

22 Cabe mencionar que de la misma postura jurídica es MARTIN TIRADO, Richard, "Análisis de la "función normativa" de los Organismos Reguladores de Inversión Privada en los Servicios Públicos. La dicotomía del rol del Estado en la actividad económica: subsidiariedad y solidaridad", en Revista Ius Et Veritas Nº 24, Pontifica Universidad Católica del Perú, Lima, 2002, p. 109. 
El procedimiento trilateral se inicia mediante la presentación de una reclamación o de oficio. Durante el desarrollo del procedimiento trilateral la Administración (el Organismo Regulador) debe favorecer y facilitar la solución conciliada de la controversia. Una vez admitida a trámite la reclamación se pondrá en conocimiento del reclamado a fin de que éste presente su descargo. Contra la resolución final recaída en un procedimiento trilateral (el Mandato específico) expedida por una autoridad u órgano sometido a subordinación jerárquica, sólo procede la interposición del Recurso de Apelación. De no existir superior jerárquico, sólo cabe plantear Recurso de Reconsideración. En este contexto, teniendo en cuenta que los Consejos Directivos de los Organismos Reguladores no cuentan con un órgano jerárquicamente superior, el reclamado, que fue vencido en el procedimiento trilateral, sólo podrá plantear un Recurso de Reconsideración, contra lo resuelto en el respectivo Mandato.

Por todo lo expuesto, podemos concluir que, a pesar de lo expresamente señalado por las leyes y reglamentos generales, en el sentido que los Mandatos se encontrarían dentro de la "función normativa" de los Organismos Reguladores, no podemos concluir en el sentido de que los Mandatos, expedidos por los Consejos Directivos de dichos organismos, sean normas reglamentarias. Lo anterior debido a que, materialmente, los referidos Mandatos se configuran como verdaderos "actos administrativos no normativos", regulados por las disposiciones del TUO de la LPAG y del TUO de la LPCA, toda vez que (i) son el acto administrativo final de un procedimiento administrativo trilateral especial, (ii) no contienen en su literalidad una norma jurídica con vocación de permanencia y (iii) se agotan o consumen con su sola aplicación a un caso concreto, a diferencia de los reglamentos. Siendo ello así, los referidos actos administrativos no normativos pueden ser válidamente cuestionados por los administrados, tanto en vía administrativa, utilizando los recursos administrativos contemplados en el TUO de la LPAG, y, posteriormente, en vía judicial, a través del proceso contencioso administrativo, regulado por la CP y el TUO de la LPCA23.

23 Es oportuno mencionar que el profesor Alejandro Moscol Salinas, ha arribado a la misma conclusión respecto a la naturaleza jurídica de los Mandatos de Interconexión de OSIPTEL. En específico, precisa que los Mandatos de Interconexión no son reglamentos, sino que son actos administrativos no normativos definitivos, expresos, de gravamen, constitutivos de derechos, resolutivos de conflictos, individuales, colegiados e impugnables. MOSCOL SALINAS, Alejandro, "Revisión de la figura del mandato de interconexión de redes y servicios públicos de telecomunicaciones desde la perspectiva del derecho administrativo", en Revista de Derecho Administrativo (CDA) No 5, 2008, pp. 93 y ss. 